\title{
Dependence of the Critical Pitting Temperature on surface roughness
}

\author{
M.H. Moayed ${ }^{\text {a }}$, N.J. Laycock ${ }^{\text {b,* }}$, R.C. Newman ${ }^{c}$ \\ a Materials Engineering Department, Faculty of Engineering, Ferdowsi University, Mashad, \\ P.O. Box 91775-1111, Iran \\ ${ }^{\mathrm{b}}$ Materials Performance Technologies, Industrial Research Limited, Gracefield Research Centre, \\ P.O. Box 31-310, Lower Hutt, New Zealand \\ ${ }^{\mathrm{c}}$ Corrosion and Protection Centre, UMIST, P.O. Box 88, Manchester M60 1QD, UK
}

Received 26 February 2002; accepted 21 October 2002

\begin{abstract}
It has been known for many years that highly alloyed stainless steels display a critical pitting temperature (CPT), which is the lowest temperature at which the growth of stable pits is possible. In the work reported here, the effect of varying surface roughness was investigated using potentiostatic and potentiodynamic CPT measurements on 904L stainless steel in $1 \mathrm{M}$ $\mathrm{NaCl}$. The results demonstrated that increasing the smoothness of the sample surface causes an increase in the CPT, even though the CPT exhibits a markedly more deterministic character than does the pitting potential. Using a potentiostatic technique, the highest measured CPT was $56{ }^{\circ} \mathrm{C}$ for a surface polished to a $3 \mu \mathrm{m}$ finish, whilst the lowest measured CPT was $46{ }^{\circ} \mathrm{C}$ for a surface ground to a 60 grit finish. These results are consistent with an explanation of the CPT proposed by Salinas-Bravo and Newman [Corros. Sci. 36 (1994) 67].

(C) 2002 Elsevier Science Ltd. All rights reserved.
\end{abstract}

Keywords: A. Stainless steel; Surface finish; C. Pitting corrosion; Critical Pitting Temperature (CPT)

\section{Introduction}

The concept of a critical pitting temperature (CPT) was introduced by Brigham and Tozer [1,2], and has since been widely used as a method of screening stainless steels and nickel-base alloys, including welding procedures $[3,4]$. For a given alloy in

${ }^{*}$ Corresponding author. Tel.: +64-4-569-0427.

E-mail address: n.laycock@matperf.com (N.J. Laycock). 
a particular test environment, stable pitting does not occur below the CPT and the breakdown observed at high anodic potentials is caused instead by transpassive dissolution. But if the CPT is exceeded, then pitting can occur and breakdown potentials drop steeply to several hundred millivolts below those required for transpassivity. CPT values are usually measured in fairly concentrated chloride solutions, but they are known to be independent of chloride concentration in the range from 0.01 to $5 \mathrm{M}[4,5]$, and of $\mathrm{pH}$ in the range 1-7 [4]. However, the CPT can be affected by high sulphate [6] or thiosulphate [7] concentrations, and different results are obtained when chlorides in the test solution are replaced with bromides [8], which form soluble complexes with Mo and eliminate most of its beneficial effect on pitting. With careful technique, the CPT can be reproduced to within 1 or $2{ }^{\circ} \mathrm{C}$.

At temperatures above the CPT, it is well known that pitting potentials tend to decrease as the sample surface roughness increases $[9,10]$. This reflects the changing characteristics of the sites available for pit initiation. Pits initiate at specific sites on the surface (usually $\mathrm{MnS}$ inclusions) and rougher surfaces generally provide sites with a more occluded geometry. It is easier to maintain a concentrated local chemistry at these occluded sites, and so (other things being equal) rougher surfaces tend to support a higher frequency of pit initiation. Many of the initiated pits are only metastable, but a higher frequency of observable pit initiation is typically associated with lower measured pitting potentials. Irrespective of the surface finish, pitting potentials are not "reproducible" but show a markedly stochastic character, unlike the CPT.

In this work we aimed primarily to establish whether or not the measured CPT is affected by the surface roughness of the samples. In addition, we planned to examine the influence of temperature on the morphology of pits, and to use this information to help elucidate the underlying mechanism behind the CPT phenomenon.

\section{Experimental procedure}

The samples used in this work were made from 904L SS, with the chemical composition shown in Table 1. The material was supplied as $6 \mathrm{~mm}$ thick plate, from which were machined a number of $5 \mathrm{~cm}$ long, $4.5 \mathrm{~mm}$ diameter rods, each with one rounded end. A threaded hole was made in the non-rounded end of the specimen, into which was inserted a screw that could be used to make electrical connection to a length of nichrome wire. Prior to each experiment, the specimens were circumferentially abraded using silicon carbide paper with deionised water as a lubricant, then rinsed with more deionised water and dried with air. A $4 \mathrm{~cm}$ length of the rod (in-

Table 1

Actual composition of 904L stainless steel used in this work

\begin{tabular}{llllll}
\hline \multirow{2}{*}{ Grade } & \multicolumn{4}{l}{ Alloying elements, wt.\% (balance Fe) } & \\
\cline { 2 - 5 } & $\mathrm{Cr}$ & $\mathrm{Ni}$ & $\mathrm{Mo}$ & $\mathrm{Mn}$ & $\mathrm{N}$ \\
\hline $904 \mathrm{~L}$ & 20.06 & 25.04 & 4.32 & 1.41 & - \\
\hline
\end{tabular}


cluding the rounded end) was immersed in the test solution during experiments, giving a total immersed area of $5-6 \mathrm{~cm}^{2}$ (decreasing with the number of times the electrode had been polished and reused).

The electrochemical cell employed in this work was a $250 \mathrm{ml}$ beaker open to the air, and suspended in a water bath to control the temperature. The solution temperature was measured using a thermometer, which was inserted into the test solution close to the working electrode, but not so close that it would interfere with the cell current flow. A commercial $\mathrm{Ag} / \mathrm{AgCl}$ electrode was used as the reference electrode for all experiments, and the stability of this electrode was compared regularly against an unused electrode. All potentials quoted in the remainder of this paper are referred to this scale. The auxiliary electrode was a bright platinum sheet, area $\sim 2 \mathrm{~cm}^{2}$, attached to a glass tube. The test solution for all experiments in this work was $1 \mathrm{M} \mathrm{NaCl}$, made up from analytical grade sodium chloride and deionised water. About $150-200 \mathrm{ml}$ of solution was used for each experiment.

\subsection{Potentiostatic CPT determination}

This procedure involves polarization of the working electrode to a potential more noble than the pitting potential, and then continuously increasing the temperature. In a given experiment, the sample was allowed to stabilize at open-circuit for 5-10 min at about $0-5^{\circ} \mathrm{C}$. An anodic potential of $750 \mathrm{mV}$ was then applied, and the electrolyte temperature was increased at a rate of $\sim 0.4{ }^{\circ} \mathrm{Cmin}^{-1}$ until stable pitting had occurred. The cell current was recorded throughout the test (except for the first $5 \mathrm{~s}$ following application of the anodic potential), and the test was stopped when the current indicated that stable pitting had continued for more than $1 \mathrm{~min}$. The CPT was defined as the temperature at which the final current rise began, indicating the onset of stable pitting.

\subsection{Potentiodynamic CPT determination}

This procedure involved polarization curves, starting from the open-circuit potential and increasing at a scan rate of $1 \mathrm{mV} \mathrm{s}^{-1}$, until the current indicated that stable pitting or transpassivity had occurred. Breakdown potentials, $E_{\mathrm{b}}$, were identified as the potential where the anodic current indicated the onset of transpassivity or stable pitting (where "stable" means that the current continued to increase for more than $1 \mathrm{~min}) . E_{\mathrm{b}}$ values were plotted as a function of the test temperature, and the CPT was defined as the temperature where $E_{\mathrm{b}}$ dropped from the transpassive range to the pitting potential range, which was typically a drop of several hundred millivolts. Between three and five tests were carried out for each temperature. For example, when five identical samples (i.e. $904 \mathrm{~L}$ rods with the same surface finish) showed breakdown by transpassive dissolution at $53{ }^{\circ} \mathrm{C}$, the same experiment was carried out just three times at $51{ }^{\circ} \mathrm{C}$, because this surface condition did not cause stable pitting at the higher temperature. 


\section{Results and discussion}

\subsection{Potentiostatic CPT determination}

Four nominally identical samples were tested for each of the following surface conditions: 60, 320, 1200 grit and $3 \mu \mathrm{m}$ diamond paste. Fig. 1 shows the anodic current recorded during testing for each of the samples with a $3 \mu \mathrm{m}$ diamond paste surface finish, and Fig. 2 shows one typical result for each of the different surface conditions.

Table 2 shows the mean and standard deviation of the data obtained for each surface condition. Clearly, the measured CPT increases as the surface roughness decreases. The lowest CPT, of about $46^{\circ} \mathrm{C}$, was measured for the specimens abraded to a 60 grit finish, whilst the highest $\mathrm{CPT}$, of about $56{ }^{\circ} \mathrm{C}$ was obtained from specimens polished to a $3 \mu \mathrm{m}$ diamond paste. The results in Table 2 also show that the measurement reproducibility increased (i.e. the standard deviation decreased) as the surface roughness decreased. The four data points for the smoothest surface were all within a $1{ }^{\circ} \mathrm{C}$ range, between 55.3 and $56.3{ }^{\circ} \mathrm{C}$ (Fig. 1). Even for the roughest surface tested, the four data points fell within a range of only $3{ }^{\circ} \mathrm{C}$, from 45 to $48{ }^{\circ} \mathrm{C}$.

\subsection{Potentiodynamic CPT determination}

Fig. 3 shows anodic polarisation curves at various temperatures for samples with a 320 grit finish, whilst Fig. 4 shows similar results for samples with a $3 \mu \mathrm{m}$ diamond

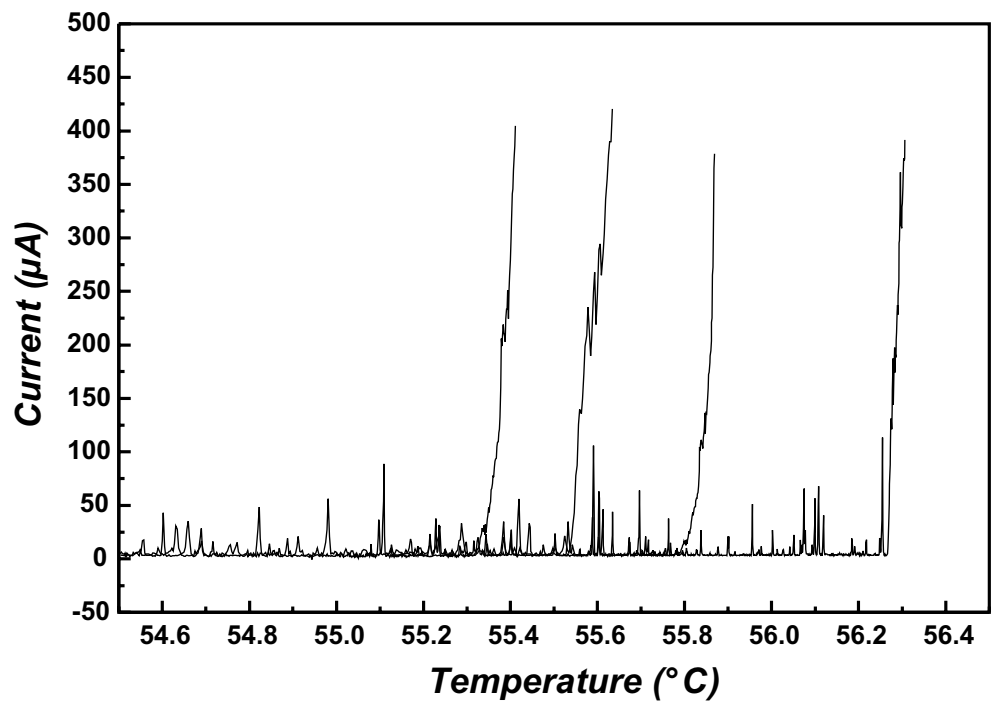

Fig. 1. Final part of four current-temperature curves obtained from potentiostatic CPT measurements on 904L stainless steel ( $3 \mu \mathrm{m}$ diamond paste finish) at $750 \mathrm{mV}$ in $1 \mathrm{M} \mathrm{NaCl}$. 


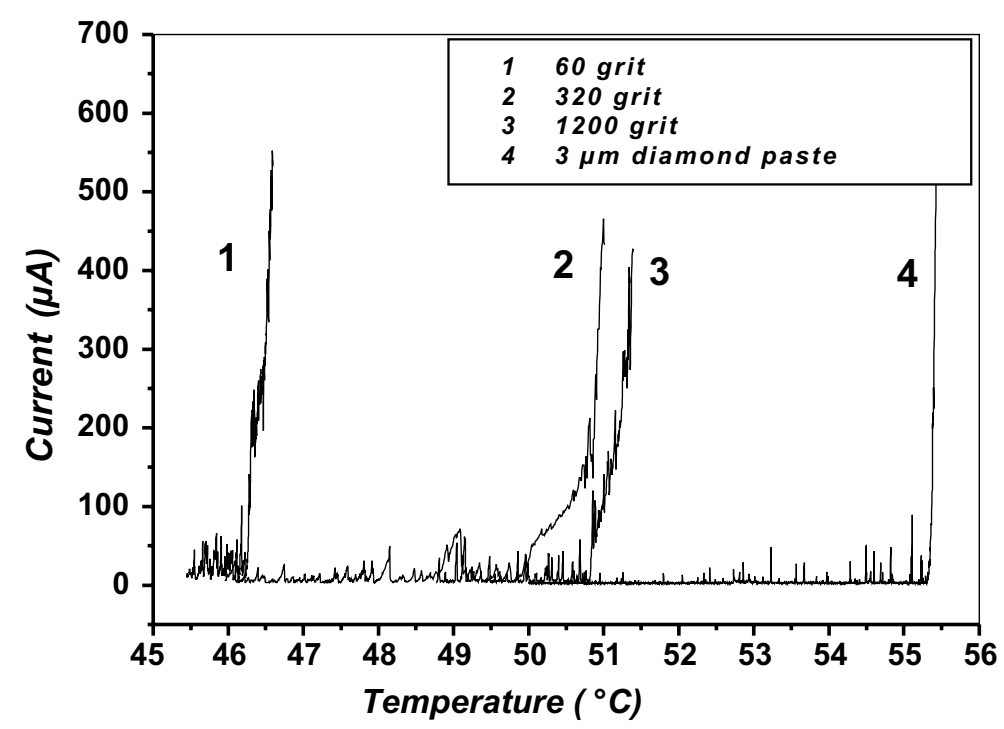

Fig. 2. Final part of four current-temperature curves obtained during potentiostatic CPT measurements on $904 \mathrm{~L}$ stainless steel (with different surface finishes) at $750 \mathrm{mV}$ in $1 \mathrm{M} \mathrm{NaCl}$.

Table 2

Average and standard deviation of potentiostatic CPT measurements on 904L stainless steel at $750 \mathrm{mV}$ in $1 \mathrm{M} \mathrm{NaCl}$

\begin{tabular}{llll}
\hline $\begin{array}{l}\text { Finishing } \\
\text { characteristics }\end{array}$ & $\begin{array}{l}\text { No. of specimen } \\
\text { tested }\end{array}$ & Average CPT $\left({ }^{\circ} \mathrm{C}\right)$ & Std. dev. $\left({ }^{\circ} \mathrm{C}\right)$ \\
\hline 60 grit & 4 & 46.7 & 0.79 \\
320 grit & 4 & 49.0 & 0.61 \\
1200 grit & 4 & 51.1 & 0.52 \\
$3 \mu$ grit & 4 & 55.7 & 0.36 \\
\hline
\end{tabular}

paste finish. Both figures show the expected transition from transpassive breakdown at relatively low temperatures (e.g. at 51 and $53{ }^{\circ} \mathrm{C}$ in Fig. 3) to breakdown by stable pitting at higher temperatures (e.g. at 55,57 and $59{ }^{\circ} \mathrm{C}$ in Fig. 3). The breakdown potentials are plotted as a function of temperature in Fig. 5. For each surface condition, these data show a step change indicating the CPT transition. As in the potentiostatic tests, the CPT for a given surface finish is very clearly defined, and increasing surface roughness causes a decrease in the CPT.

Fig. 5 suggests potentiodynamically determined CPT values of about 47 and 55 ${ }^{\circ} \mathrm{C}$ for the 320 grit and $3 \mu \mathrm{m}$ diamond paste surface finishes respectively. These can be compared with the corresponding potentiostatically determined values of about 49 and $56{ }^{\circ} \mathrm{C}$ (Table 2). Although identical results were not obtained from the two techniques, the differences are small - of the order of 1 or $2{ }^{\circ} \mathrm{C}-$ and both methods clearly reveal the influence of surface roughness. 


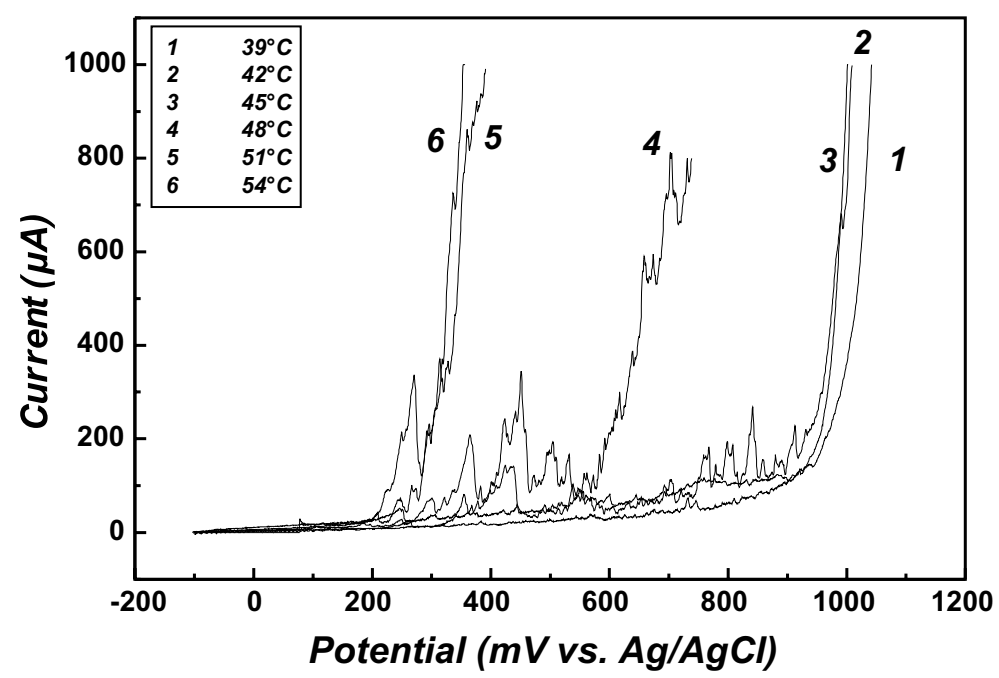

Fig. 3. Anodic polarisation curves for $904 \mathrm{~L}$ stainless steel (320 grit finish) in $1 \mathrm{M} \mathrm{NaCl}$ at different temperatures. Note the peak in pitting intensity at intermediate potentials below the CPT.

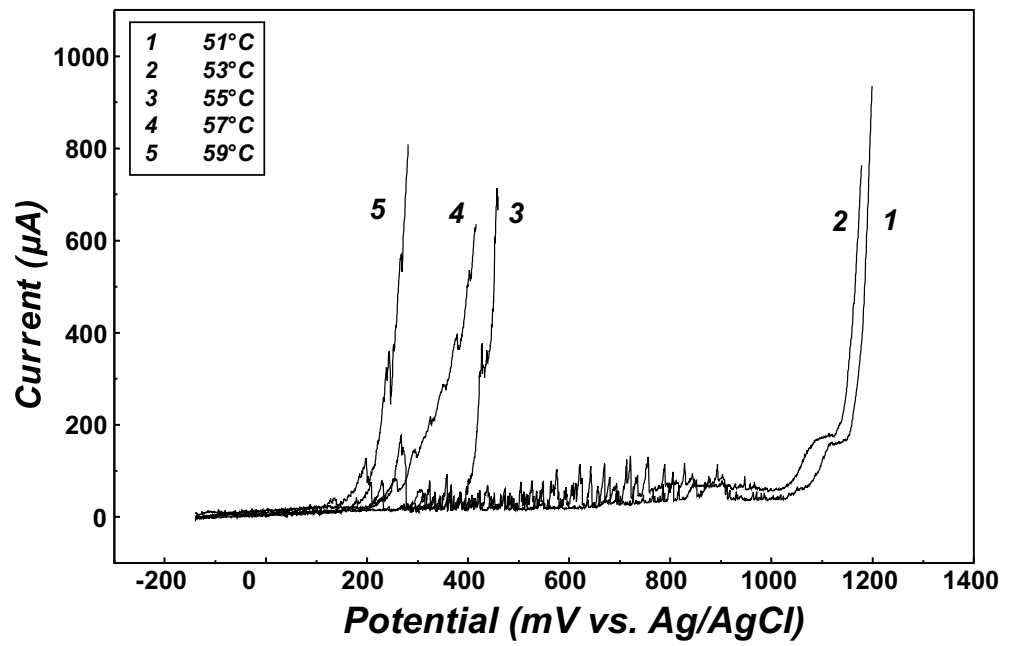

Fig. 4. Anodic polarization curves for $904 \mathrm{~L}$ stainless steel $(3 \mu \mathrm{m}$ diamond paste finish) in $1 \mathrm{M} \mathrm{NaCl}$ at different temperatures.

In previous work, we observed a peak in metastable pitting activity on 904L stainless steel at about 400-500 $\mathrm{mV}$ when the temperature was below the CPT [5]. The same effect can be seen at temperatures below the CPT in Figs. 3 and 4. For the 


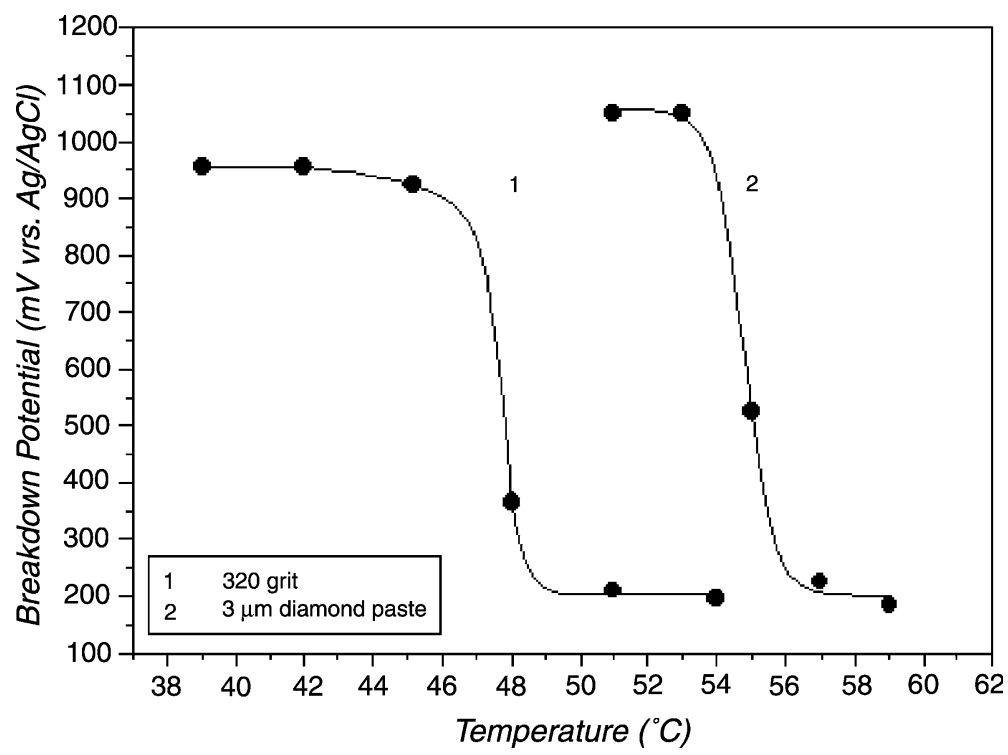

Fig. 5. Breakdown potentials as a function of temperature for $904 \mathrm{~L}$ stainless steel (with two different surface finishes) in $1 \mathrm{M} \mathrm{NaCl}$.

relatively coarse 320 grit surface finish, the largest metastable pit transients are seen around $350-450 \mathrm{mV}$ (Fig. 3). For the finer $3 \mu \mathrm{m}$ finish, the metastable pitting intensity clearly decreases as the potential increases above about $800 \mathrm{mV}$ (Fig. 4). It is also worth noting that the shape of the early part of the transpassive region of the polarisation curve is affected by the surface roughness, with a small shoulder being clearly visible at about $1100 \mathrm{mV}$ in Fig. 4, but indiscernible in Fig. 3. However, further investigation of this effect is outside the scope of this work.

\subsection{Pit morphology}

The current-time series in Figs. 1 and 2, and the polarisation curves in Figs. 3 and 4 , show current transients due to metastable pitting at temperatures below the CPT. In fact, although not shown in these figures, similar pitting transients were observed in these experiments at temperatures as low as $30^{\circ} \mathrm{C}$. And in previous work, we have seen small metastable pitting events on 904L stainless steel at as low as $5{ }^{\circ} \mathrm{C}$ [11]. These pits act as the initiation events for crevice corrosion, with the critical crevice temperature (CCT) being much lower than the CPT.

After some of the potentiostatic CPT determinations, the samples were examined using a scanning electron microscope (SEM). Pits were distributed evenly over the sample surface, without any noticeable increase in intensity at the waterline or on the end of the rod. These observations suggested a bimodal distribution of pitting damage: a population of "small pits", up to about $30 \mu \mathrm{m}$ diameter, which did not 
usually have a lacy metallic cover; and a second population of "large pits", greater than about $100 \mu \mathrm{m}$ in diameter, which did usually have a lacy metallic cover. We assume that the small pits were mostly the result of metastable events that repassivated during the tests. For example, in Fig. 2 there is a relatively large metastable pit transient beginning at about $48{ }^{\circ} \mathrm{C}$, which incorporates about $30 \mu \mathrm{C}$ of charge. Making the usual assumptions [9], this corresponds to a hemispherical pit with a diameter of about $30 \mu \mathrm{m}$. The vast majority of the metastable transients in this work were smaller than this one. Consequently, the larger pits observed in this work are assumed to be mostly the result of stable pit growth terminated only by the end of the test. However, it is considered possible that some of the large pits had repassivated before the end of the test and should, therefore, be properly referred to as only metastable.

Since stable pits can only be formed above the CPT, it is reasonable to assume that the large pits were almost exclusively formed at temperatures above the CPT. Furthermore, all these tests were carried out at a constant potential of $+750 \mathrm{mV}$, which is well above the average pitting potential for any of the tested surface conditions at temperatures above the CPT. Consequently, we assume that any pit initiated above the CPT would have a very high probability of becoming stable, and that very few of the small pits would have been formed at temperatures above the CPT. Finally, the data from every test indicate a high frequency of metastable pitting at temperatures below the CPT, which is consistent with the idea that the small pits were predominantly formed below the CPT.

For pitting at temperatures above the CPT, it is well established that a concentrated local environment must be maintained in order to sustain pit growth, and that increasing the potential results in higher pit current densities until salt precipitation intervenes. At the relatively high potential applied in these potentiostatic CPT tests, we would expect most pits to precipitate a salt film at an early stage of their growth. Consequently, we would expect all of the large pits and most of the small pits observed in this work to have the polished interior surface and dish-shaped profile that result from diffusion-controlled dissolution beneath a salt layer $[9,12,13]$. This was indeed the case, with the interior of a typical polished pit being shown in Fig. 6(a). Some of the small pits had rougher internal surfaces, suggesting that a salt film had not been present during (or at least in the last part of) their growth, as shown in Fig. 6(b).

In summary, there were two populations of pits on the samples used for potentiostatic CPT determination:

1. Small pits. These were mostly formed by metastable pitting below the CPT, and had a final diameter less than about $30 \mu \mathrm{m}$. They had either rough or polished interior surfaces, but did not have a lacy metallic cover. Examples are shown in Fig. 6 for two different surface finishes.

2. Large pits. These were mostly formed by stable pitting above the CPT, and had a final diameter greater than about $100 \mu \mathrm{m}$. They tended to have polished interior surfaces, dish-shaped profiles, and lacy metallic covers. Two examples are shown in Fig. 7. 


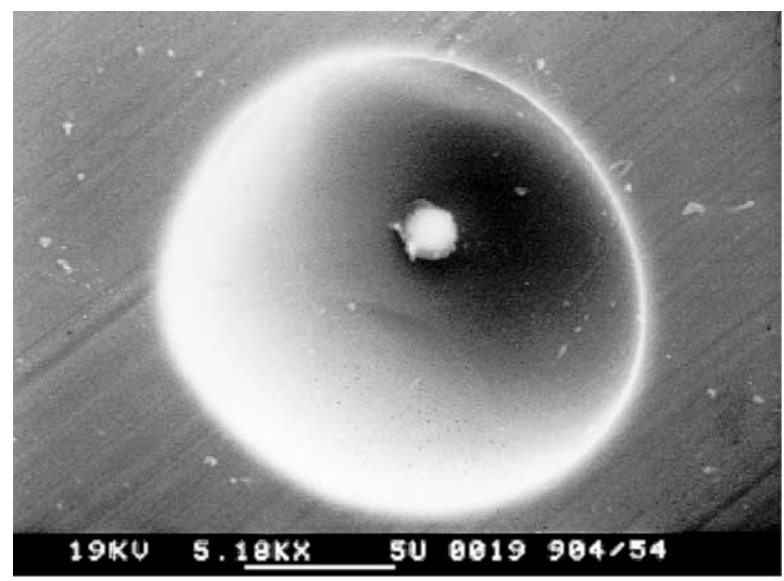

(a)

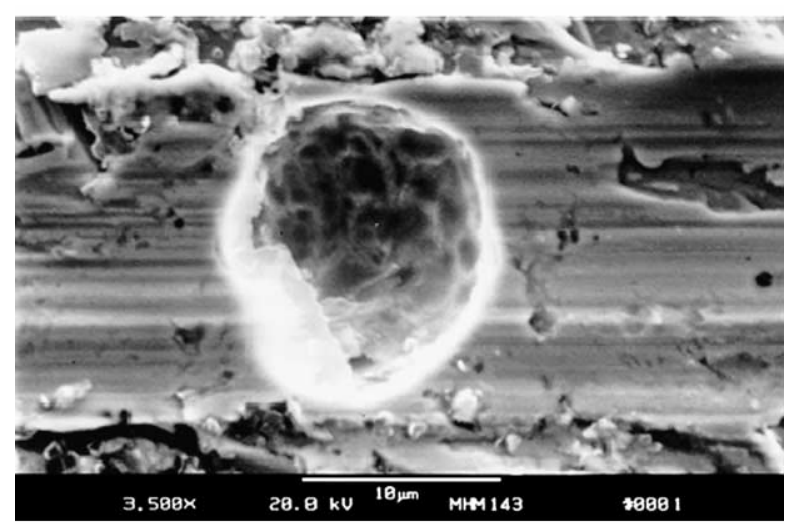

(b)

Fig. 6. SEM photomicrographs of small pits formed on 904L stainless steel during potentiostatic CPT tests at $750 \mathrm{mV}$ in $1 \mathrm{M} \mathrm{NaCl}$ : (a) from a sample with a $3 \mu \mathrm{m}$ diamond paste finish and (b) from a sample with a 320 grit finish.

\subsection{The influence of surface roughness on the CPT}

Because a propagating pit must maintain at least a near-saturated local chemistry, it must propagate at a current density close to the diffusion-limited anodic current density, $i_{\text {lim }}$. To explain the CPT, Salinas-Bravo and Newman [14] suggested the existence in the most concentrated possible pit solution of a critical current density for passivation $\left(i_{\text {crit }}\right)$, which increases with temperature more rapidly than does $i_{\text {lim }}$. Following this argument, the CPT would be the temperature where these two current densities are equal to each other. At lower temperatures, passivation would prevent pits from achieving the current density necessary to maintain a concentrated local chemistry. At higher temperatures, salt precipitation would prevent $i_{\text {crit }}$ from being 


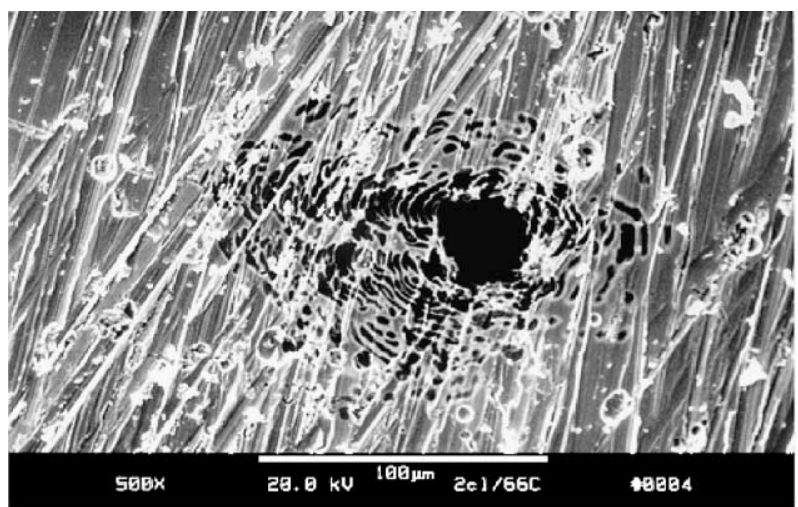

(a)

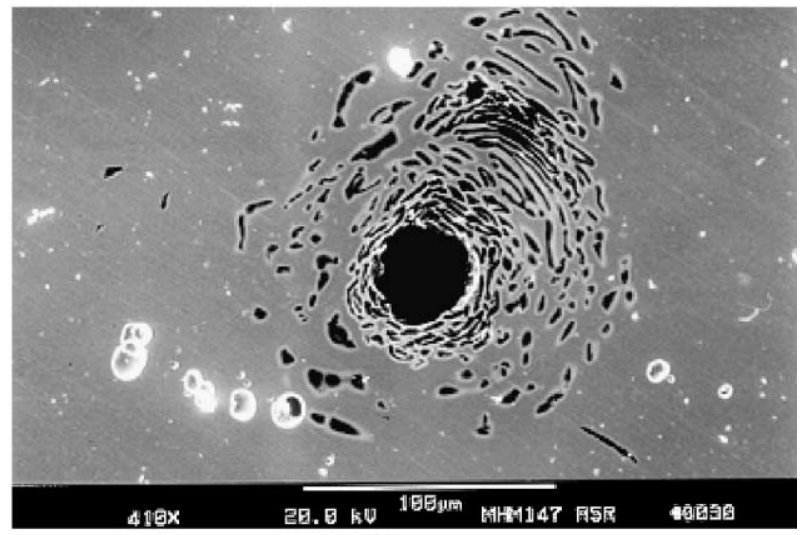

(b)

Fig. 7. SEM photomicrographs of large pits formed on 904L stainless steel during potentiostatic CPT tests at $750 \mathrm{mV}$ in $1 \mathrm{M} \mathrm{NaCl}$ : (a) from a sample with a 320 grit finish and (b) from a sample with a $3 \mu \mathrm{m}$ diamond paste finish.

reached, and so would prevent repassivation. This model is shown schematically in Fig. 8(a), in which the effective diffusion length, $h$, is used to explain the difference between the CPT and CCT [15]. For 904L stainless steel (with a particular crevice arrangement) we have previously reported a CCT of about $20^{\circ} \mathrm{C}$ [11], which suggests an approximately $30^{\circ} \mathrm{C}$ decrease in critical temperature due to an increase in $h$ from $1-10 \mu \mathrm{m}$ for pits to $0.1-1 \mathrm{~mm}$ for crevices.

The above argument is complicated by the fact that whilst $i_{\text {crit }}$ is independent of pit size and shape, $i_{\text {lim }}$ is not. Pits generally initiate at surface-emergent inclusions, which have a distribution of size and shape, and are also distributed randomly across the sample surface such that they coincide with both peaks and troughs in the surface profile. Furthermore, the current density also changes as a pit grows: detailed analysis reveals a sequence of sharp increases followed by slower decays, giving an approximately constant average value [9]. The sharp increases are thought to be 


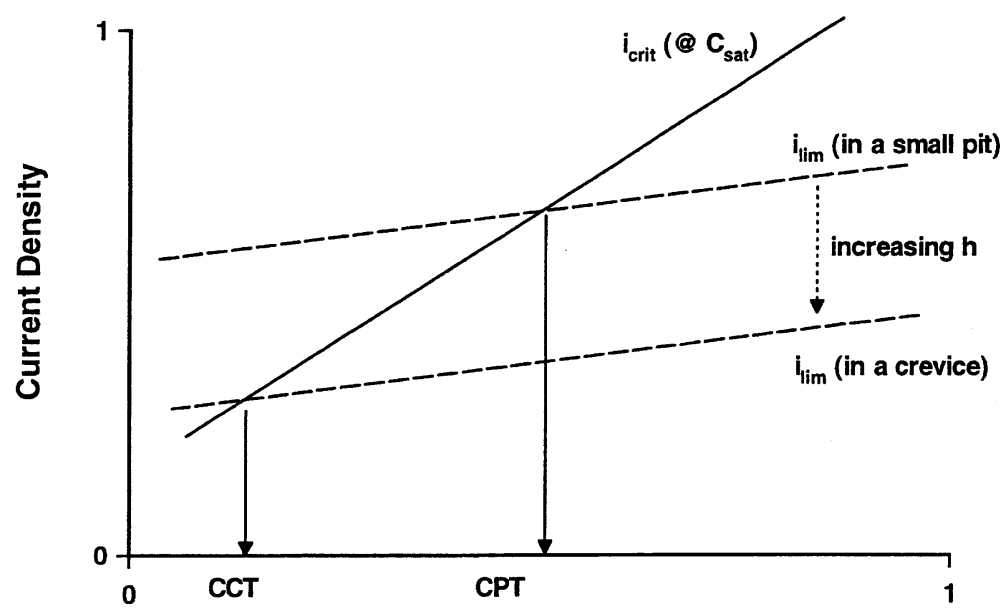

(a)

Temperature

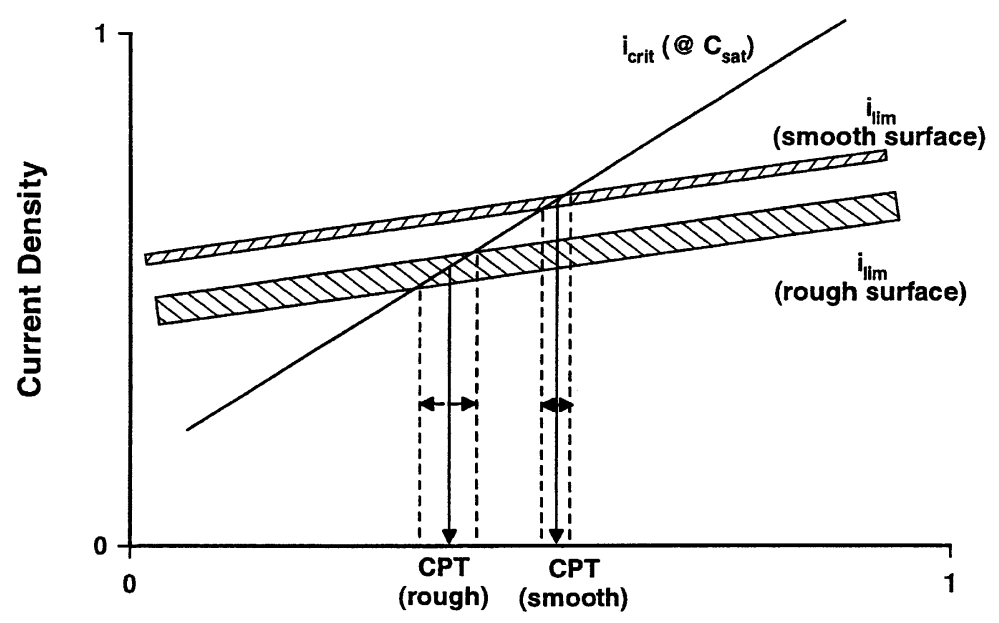

(b)

Temperature

Fig. 8. Schematic diagram showing $i_{\text {lim }}$ and $i_{\text {crit }}$ (at $C_{\text {sat }}$ ) as a functions of temperature. Below the CPT, a stable corroding state cannot be reached, because the necessary current density exceeds $i_{\text {crit }}$ : (a) the effect of increasing the effective diffusion length, from that of a pit to that of a crevice and (b) the effect of having multiple possible pit initiation sites, creating a distribution of possible $h$ values for a given sample.

caused by formation of new holes in the pit cover, or even by partial collapses of the cover $[9,16,17]$. Thus, over a population of pits, the value of $i_{\text {lim }}$ in the early (metastable) stage of pit growth is distributed over a range decided mainly by the geometry of the possible initiation sites. Because the CPT is the temperature where $i_{\text {crit }}=i_{\text {lim }}$, each individual pit can be considered to have its own CPT value. For a sample with a large number of possible initiation sites, there is a range of possible CPT values that could be measured in any given experiment. 
In a potentiostatic experiment to measure the CPT of a particular sample, a large number of pits are usually initiated. At relatively low temperatures, $i_{\text {crit }}$ is too low for stable growth and so all the pits repassivate. But once the temperature increases into the range of possible CPT values, a pit that satisfies the requirements for stable growth will eventually initiate. The temperature at which this happens will be the measured CPT for that particular sample, but the results obtained for a number of nominally identical samples will be distributed over a range of temperatures as shown in Fig. 8(b). Increasing the surface roughness of the samples would create the possibility of pit initiation at more occluded sites; i.e. at the bottom of the increasingly deep troughs in the surface profile. As in the case of crevice corrosion, this would increase the maximum possible value of $h$, and would therefore decrease the lowest possible value of the CPT. At the same time, even the roughest surfaces can still have initiation sites in quite open positions, such as the top of the peaks in the surface profile. Thus, increasing surface roughness would tend to increase the range of possible $h$ values of the available pit initiation sites, thereby increasing the possible range of CPT values for that surface condition. Overall, following the ideas of Salinas-Bravo and Newman [14], increasing surface roughness should lead to a decrease in the mean and an increase in the standard deviation of the CPT, as shown in Fig. 8(b).

In this model, at temperatures below the CPT, small pits are at risk of repassivation each time the structure of the pit cover changes (e.g. by formation of a new hole or by partial collapse). At relatively low potentials these events can result in dilution of the local chemistry, and at higher potentials the current density might rise to $i_{\text {crit }}$ even in the saturated pit solution, with both possibilities leading to repassivation. At temperatures above the CPT, the latter mechanism is not operative. In these conditions, some pits eventually reach a critical size above which the probability of repassivation becomes very low and their growth can be considered stable. In the present work, the "small pits" had a maximum diameter of about $30 \mu \mathrm{m}$, and were mostly even smaller than that (Fig. 6). Thus, at least on relatively coarse surfaces (such as a 320 grit finish), the majority of metastable pits suffer a fatal crisis in stability at a size of the same order as the surface roughness. Hence, it is reasonable to conclude that surface roughness affects both the pitting potential and the CPT through its effect on the value of $i_{\text {lim }}$ during metastable pit growth. Nevertheless, for a given surface finish, the CPT transition is very sharp compared with the scatter usually found in pitting potential measurements.

In summary, the observed effect of surface roughness is qualitatively consistent with the model of the CPT proposed by Salinas-Bravo and Newman [14], which is also supported by recent artificial pit experiments and finite element simulations of pit growth $[18,19]$. However, it is not clear as yet whether this model is sufficient to explain the sharpness of the CPT transition. We have previously suggested [5] a slight modification to the model, in which salt precipitation below the CPT leads to passivation in a manner similar to that of iron in sulphuric acid [20], and further work is in progress to resolve this issue. For practical purposes, such as screening weld procedures, it is clearly important to specify a surface finish for CPT measurements. However, other aspects of the measurement methodology, such as the 
choice of potential in potentiostatic tests, are at least as important. This has been discussed in considerable detail by Arnvik and Bisgård [21], and care should be taken to consider their findings when comparing CPT values obtained from different sources.

\section{Conclusions}

1. Potentiostatic and potentiodynamic measurement methods generate very similar values for the CPT. In this work, the results differed by up to about $2{ }^{\circ} \mathrm{C}$.

2. A series of CPT measurements in nominally identical conditions produces a very narrow distribution of results. In this work, the standard deviation of the CPT increased with surface roughness, reaching a maximum of only $0.79{ }^{\circ} \mathrm{C}$ for the 60 grit finish.

3. The CPT decreases as the surface roughness increases. Using a potentiostatic method, CPT values of 46 and $56{ }^{\circ} \mathrm{C}$ were measured for $904 \mathrm{~L}$ stainless steel with, respectively, 60 grit and $3 \mu \mathrm{m}$ diamond paste finishes.

4. Below the CPT, metastable pitting generates small pits with a final diameter typically of less than $30 \mu \mathrm{m}$. These pits can have either rough or polished interior surfaces, and do not usually have a lacy metallic cover.

5. Above the CPT, pitting at high applied potentials generates stable pits that typically have a polished interior surface, a dish-shaped profile, and a lacy metallic cover.

6. These results are consistent with the explanation of the CPT proposed by SalinasBravo and Newman, although some refinement of the model is probably necessary.

\section{Acknowledgements}

MHM is grateful to the Iran Ministry of Science, Research and Technology for financial support, whilst NJL thanks the New Zealand Foundation for Research, Science and Technology for support under contract CO8X0012. We also thank Donal Krouse of Industrial Research Limited for helpful discussions, and Avestapolarit for supplying the 904L stainless steel used in this work.

\section{References}

[1] R.J. Brigham, E.W. Tozer, Corrosion 29 (1973) 33.

[2] R.J. Brigham, E.W. Tozer, Corrosion 30 (1974) 161.

[3] J.W. Oldfield, Inter. Met. Rev. 32 (1987) 153.

[4] R. Qvarfort, Corros. Sci. 29 (1989) 987.

[5] N.J. Laycock, M.H. Moayed, R.C. Newman, J. Electrochem. Soc. 145 (1998) 2622.

[6] M.H. Moayed, R.C. Newman, Corros. Sci. 40 (1998) 519.

[7] N.J. Laycock, Corrosion 55 (1999) 590. 
[8] P. Ernst, M.H. Moayed, N.J. Laycock, R.C. Newman, in: M.B. Ives, B.R. Macdovgall, J. Bardwell (Eds.), Passivity of Metals and Semiconductors VIII, PV 99-42, The Electrochemical Society, Pennington NJ, USA, 1999, p. 665.

[9] P.C. Pistorius, G.T. Burstein, Phil. Trans. Roy. Soc. Lond. A 341 (1992) 531.

[10] G.T. Burstein, P.C. Pistorius, Corrosion 51 (1995) 380.

[11] N.J. Laycock, J. Stewart, R.C. Newman, Corros. Sci. 39 (1997) 1791.

[12] P. Ernst, N.J. Laycock, M.H. Moayed, R.C. Newman, Corros. Sci. 39 (1997) 1133.

[13] R.C. Alkire, K.P. Wong, Corros. Sci. 28 (1988) 411.

[14] V.M. Salinas-Bravo, R.C. Newman, Corros. Sci. 36 (1994) 67.

[15] N.J. Laycock, R.C. Newman, in: G.S. Frankel, J.R. Scully (Eds.), Proceedings of the Research Topical Symposium: Localized Corrosion, NACE, Houston, TX, 2001, p. 165.

[16] G.S. Frankel, L. Stockert, F. Hunkeler, H. Boehni, Corrosion 43 (1987) 429.

[17] D.E. Williams, J. Stewart, P.H. Balkwill, Corros. Sci. 36 (1994) 1213.

[18] N.J. Laycock, S.P. White, in: Proceedings of CAP 2000, Paper \# 43, ACA, Auckland, New Zealand, November 19-22, 2000.

[19] N.J. Laycock, S.P. White, D. Krouse, in: P. Schmuki, D.J. Lockwood, Y.H. Ogata, H.S. Isaacs (Eds.), Pits and Pores II: Formation, Properties and Significance for Advanced Materials, PV 2000-25, The Electrochemical Society, Pennington NJ, USA, 2000, p. 100.

[20] T.R. Beck, J. Electrochem. Soc. 129 (1982) 2412.

[21] P.E. Arnvig, A.D. Bisgård, ACOM 3 (1996) 2. 